\title{
Productivity and economics of potato (Solanum tuberosum) + frenchbean (Phaseolus vulgaris) intercropping system
}

\author{
RAJIV \\ Vegetable Research Station, C.S.A. University of Agriculture and Technology, KANPUR (U.P.) INDIA \\ (Email : rajiv.agro69@gmail.com)
}

\begin{abstract}
A field experiment was conducted during Rabi 2010-11 to 2012-13 at Vegetable Research Station Kalyanpur, Kanpur (U.P.) in which intercroppings of potato + frenchbean in 1:1, 2:1 and 1:2 row ratios were tested against sole crops of potato and frenchbean. Based on 3 year results, intercropping adversely affected the yield of potato from 30.2 to 68.2 per cent and that of frenchbean from 58.7 to 82.3 per cent. Total productivity in terms of potato equivalent yield was highest of $38.48 \mathrm{t} / \mathrm{ha}$ in sole potato which also earned significantly highest of Rs. 151149/ha net return. Among intercroppings, 2:1 row ratio of potato + frenchbean registered higher productivity of 30.76 t/ha potato equivalent yield and Rs. 126619/ha net return. All intercroppings recorded LER value less than one which showed that in present study, intercropping neither proved productive nor profitable compared to sole potato. Further studies are needed in this respect.
\end{abstract}

Key Words : Potato, Frenchbean, Intercropping, Productivity, Economics

View Point Article : Rajiv (2015). Productivity and economics of potato (Solanum tuberosum) + frenchbean (Phaseolus vulgaris) intercropping system. Internat. J. agric. Sci., 11 (2) : 282-285.

Article History : Received : 07.10.2014; Revised : 20.05.2015; Accepted : 27.05.2015 